\title{
Avaliação física $\epsilon$ mecânica de concreto com a inserção de resíduos de pneus inservíveis
}

\author{
CAMILA SIMONETTI - DOUTORA* \\ SUINFRA - UFRGS \\ itt Performance - UNISINOS \\ LUIZ CARLOS PINTO DA SILVA FILHO - DoUTOR, PROFESSOR \\ PPGCI UFRGS
}

BERNARDO FONSECA TUTIKIAN - DouTOR, ProfESSOR

\begin{abstract}
RESUMO
A ADIÇÃO DE PARTÍCULAS DE BORRACHA E DE FIBRAS METÁLICAS PROVENIENTES DA RECICLAGEM DE PNEUS INSERVÍVEIS EM ELEMENTOS DE CONCRETO VEM SENDO OBJETO DE INVESTIGAÇÃO EM DIVERSAS PESQUISAS, UMA VEZ QUE A INCORPORAÇÃO DESSES RESÍDUOS PODE QUALIFICAR PROPRIEDADES DO CONCRETO, BEM COMO TRAZER BENEFÍCIOS SOCIOAMBIENTAIS E ECONÔMICOS. O PRESENTE ARTIGO BUSCA CARACTERIZAR AS PROPRIEDADES FÍSICAS E MECÂNICAS DE CONCRETOS COM A INCORPORAÇÃO DE RESÍDUOS DE PNEU INSERVIVIEL. O PROGRAMA EXPERIMENTAL ENVOLVEU ENSAIOS DE ABATIMENTO NO ESTADO

FRESCO, RESISTÊNCIA À COMPRESSÃO, MÓDULO DE ELASTICIDADE E OBTENÇÃO DE IMAGENS POR TOMÓGRAFO NO ESTADO ENDURECIDO. OS RESULTADOS OBTIDOS APONTARAM PARA REDUÇÃO DA TRABALHABILIDADE NO ESTADO FRESCO PARA TODAS AS MISTURAS. EM RELAÇÃO À RESISTÊNCIA À COMPRESSÃO E AO MÓDULO DE ELASTICIDADE, OS RESULTADOS NÃO APONTARAM DIMINUIÇÃO SIGNIFICATIVA. DE FORMA GERAL, É POSSÍVEL EVIDENCIAR MELHORA DE CERTAS CARACTERÍSTICAS DOS CONCRETOS COM INSERÇÃO DE BORRACHA E DE FIBRA METÁLICA RECICLADAS DE PNEUS INSERVIVEIS.
\end{abstract}

Palavras-chave: pneu inservível, concreto com borracha, concreto reforçado com fibra de aço, resistência à compressão.

\section{INTRODUÇÃO}

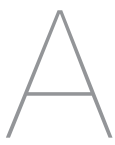

deposição inadequada de pneus inservíveis é um caso de destaque quando se discute a mitigação de impactos sanitários e ambientais, fato que tem motivado várias pesquisas sobre possíveis métodos de aproveitamento desse tipo de rejeito.

A construção civil vem se mostrando como uma consumidora potencial de resíduos, dada a sua capacidade de absorver grandes quantidades de material, a busca por alternativas para superar a escassez de matérias-primas naturais, o interesse em reduzir a pegada ambiental das obras e a boa capacidade de encapsulamento de diversos contaminantes pelas matrizes de concreto.
O aproveitamento de partículas de pneus inservíveis no concreto já tem sido objeto de estudo de diversos pesquisadores, demonstrando ser uma alternativa de disposição nobre e adequada para esses resíduos, transformando-os em um coproduto comercializável.

O concreto é um dos materiais mais utilizados em obras e em empreendimentos brasileiros. Portanto, é imprescindível o controle de qualidade utilizado por meio de uma série de ensaios, como os físicos e os mecânicos, de forma a garantir uma indicação geral da qualidade da mistura.

Ao inserir a fibra metálica reciclada ou o agregado reciclado de borracha ao concreto, obtém-se um novo material compósito que deve ser avaliado quanto ao seu desempenho nos estados fresco e endurecido.

Dentro desse contexto, o presente trabalho buscou avaliar o comportamento de concretos elaborados com material reaproveitado de pneus inservíveis, fibra metálica reciclada e agregado reciclado de borracha através da caracterização da trabalhabilidade no estado fresco e das propriedades físicas e mecânicas no estado endurecido.

\section{MATERIAIS E MÉTODOS}

\section{I Materiais utilizados}

As fibras metálicas recicladas utilizadas são originadas de pneus inservíveis, 

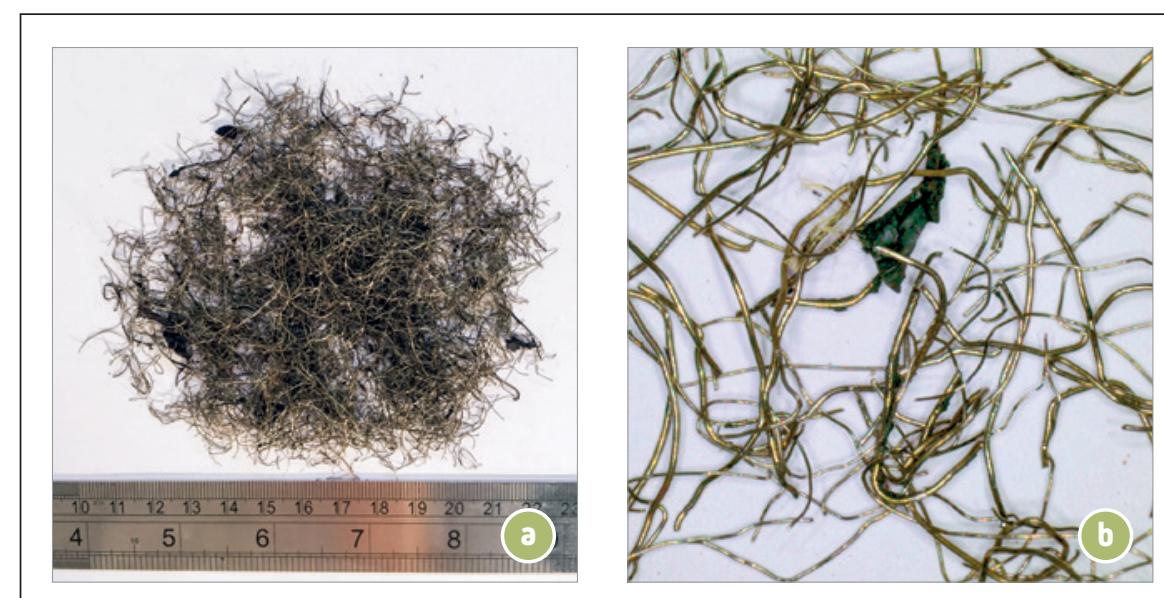

no estudo têm origem basáltica, sendo tipo 1, com diâmetro máximo de 12,5 mm e módulo de finura igual a 6,07; e tipo 2, com diâmetro máximo de 19 mm e módulo de finura igual a 7,05.

O cimento utilizado para a confecção dos concretos foi o tipo CP-V ARI, e $\mathrm{o}$ aditivo empregado foi um superplastificante de alto desempenho.

\subsection{Dosagem $\in$ mistura dos concretos}

\section{Figura 1}

Amostra da fibra de aço reciclada: (a) máquina fotográfica comum e (b) microscópio digital (marca Zeiss, modelo Smartzoom 5)

apresentadas na Figura 1, com diâmetro médio de 0,25 mm e comprimento médio de 19,26 mm.

É possível verificar na Figura 1b que o formato e o comprimento da fibra reciclada não são padronizados, muitas vezes contorcidos e com propriedades geométricas irregulares, devido ao próprio processo de trituração mecânica de obtenção do resíduo. Durante a concretagem, o processo de inserção das fibras metálicas recicladas no misturador foi manual e foi registrada grande dificuldade de dispersão homogênea da fibra, dada a sua tendência de aglomeração.

Apesar dos cuidados tomados para o espalhamento homogêneo da fibra metálica reciclada, observou-se a formação de ouriços no concreto fresco. As aglomerações de fibras metálicas no concreto são prejudiciais, pois não promovem uma mistura homogênea e favorecem pontos fracos e porosos no local onde cada grumo se forma.

O agregado reciclado de borracha é originado de pneus inserviveis que passaram por um processo de trituração mecânica, sendo fornecido na faixa gra- nulométrica de 0,7 a $2 \mathrm{~mm}$, conforme a Figura 2. O uso de um microscópio digital com ampliação da imagem na Figura 2b permite visualizar a morfologia irregular dos grânulos de borracha de pneu.

Os agregados miúdos utilizados são areais de origem quartzosa, dragada do rio Jacuí/RS, sendo tipo 1, com diâmetro máximo de 0,60 mm e módulo de finura igual a 0,93; e tipo 2, com diâmetro máximo de 2,36 mm e módulo de finura igual a 1,81.

Os agregados graúdos utilizados

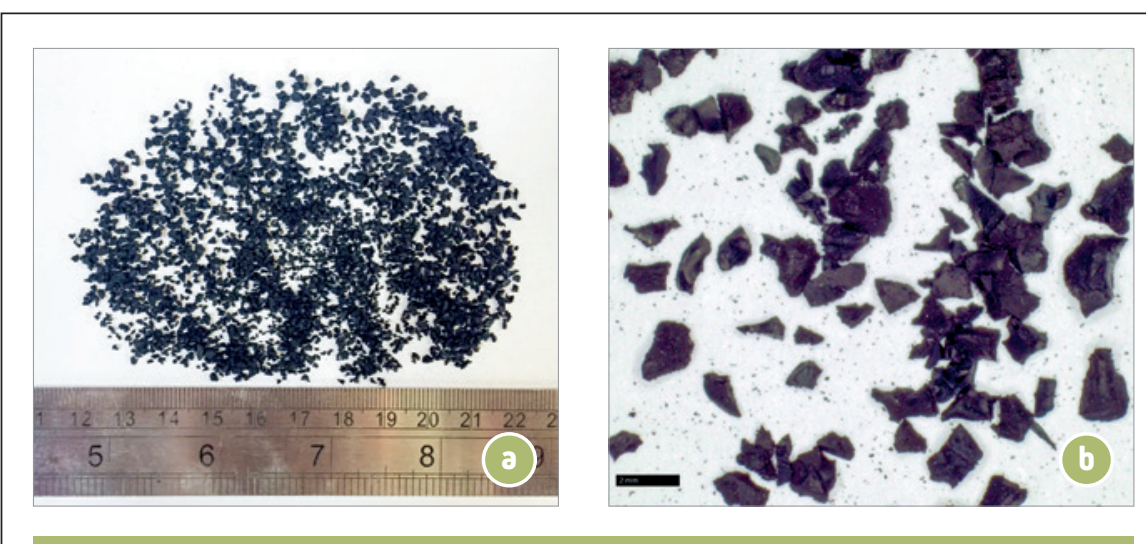

Figura 2

Amostra do agregado reciclado de borracha: (a) máquina fotográfica comum e (b) microscópio digital (marca Zeiss, modelo Smartzoom 5) 
Tabela 1 - Avaliação do volume ocupado por vazios e por fibras metálicas

\begin{tabular}{|ccc|}
\hline Traço & $\begin{array}{r}\text { Percentual da amostra } \\
\text { ocupado por vazios }\end{array}$ & $\begin{array}{c}\text { Percentual da amostra } \\
\text { ocupado por fibras } \\
\text { metálicas recicladas }\end{array}$ \\
\hline B0R5\% & $3,25 \%$ & - \\
\hline BOR10\% & $3,86 \%$ & - \\
\hline FIB0,5\% & $1,87 \%$ & $0,07 \%$ \\
\hline FIB1,5\% & $1,44 \%$ & $0,69 \%$ \\
\hline
\end{tabular}

aditivo superplastificante foi utilizado com percentual fixo de 0,36\% sobre a massa do cimento em todos os concretos confeccionados.

A etapa de produção dos corpos de prova cilíndricos foi realizada em central dosadora automatizada de uma fábrica de pré-moldados no Rio Grande do Sul, sendo um misturador do tipo planetário com eixo vertical.

\subsection{Caracterização $\epsilon$ ensaios realizados}

Cada traço foi moldado em uma única etapa de concretagem. No estado fresco, após cada procedimento de mistura, foi efetuado ensaio de aba- timento do tronco de cone de acordo com a norma vigente no momento, a NBR NM 67 (ABNT, 1998).

$A$ resistência à compressão foi aferida conforme a NBR 5739 (ABNT, 2007), aos 3, 7 e 28 dias. O módulo de elasticidade foi determinado de acordo com a NBR 8522 (ABNT, 2017), aos 28 dias. A caracterização mecânica dos concretos empregou corpos de prova cilíndricos de 100 mm de diâmetro e 200 mm de altura, utilizou uma prensa hidráulica INSTRON-EMIC, modelo 23-300, com capacidade de 2.000 kN, localizada no Laboratório de Segurança Estrutural do Instituto Tecnológico em Desempenho e Construção Civil (itt Performance), na Universidade do Vale do Rio dos Sinos (UNISINOS).

A caracterização física foi realizada a partir de uma inspeção por tomografia 3D em pequenas amostras cilíndricas com diâmetro de 25 mm e altura de 30 mm. O equipamento é da marca Nikon ${ }^{\circledR}$, modelo XT V 160, e utiliza tecnologia de análise de raios $X$ com detectores eletrônicos em vez de filmes radiológicos, com a apreciação da imagem em tempo real. A tomografia computadorizada de raios $X$ foi adotada por ser uma técnica não destrutiva que permite avaliar o volume de vazios e o volume ocupado pelas fibras metálicas recicladas nas amostras. A visualização e a análise dos dados utilizaram voxels como monitores volumétricos, sendo que a capacidade de processamento do software VGSTUDIO MAX ${ }^{\circledR}$, versão 2.2.5, é de 8 voxels ao infinito. $O$ ensaio e a análise de imagens foram realizados no itt Fuse, na UNISINOS.

\section{RESULTADOS E DISCUSSÕES}

\section{I Caracterização física}

A análise do espaço ocupado por
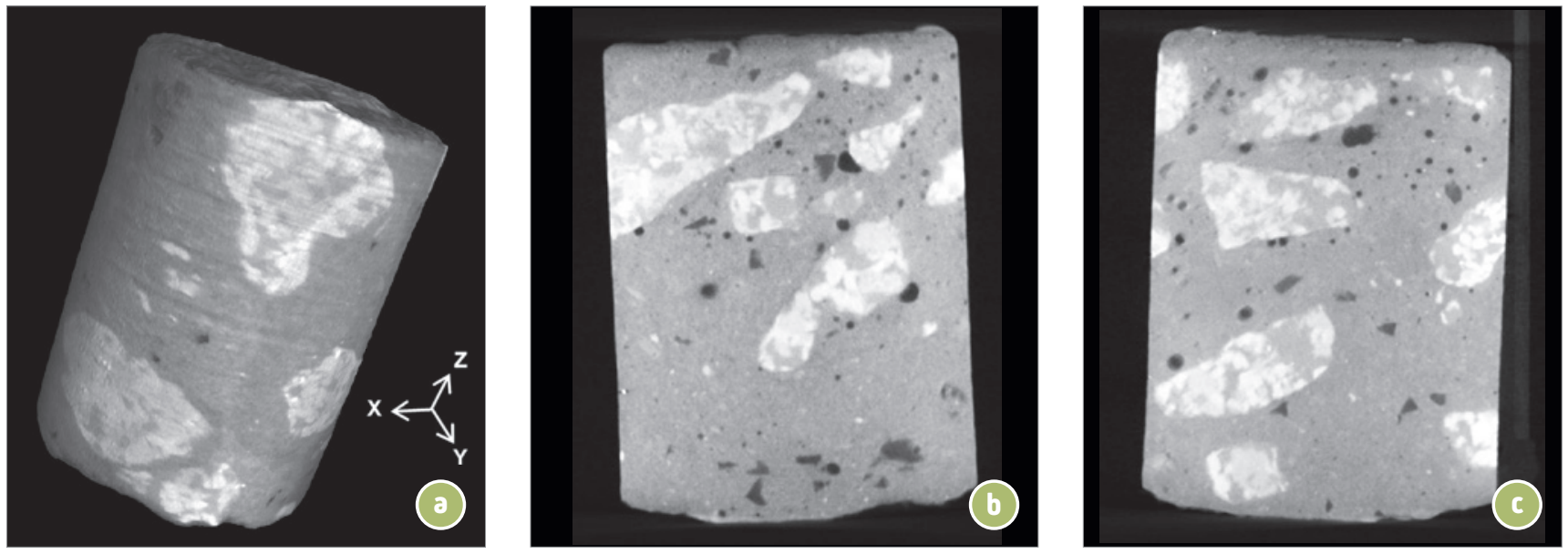

Figura 3

BOR5\%: (a) imagem tridimensional da amostra (b) imagem bidimensional conforme eixo ZX e (c) conforme eixo ZY 


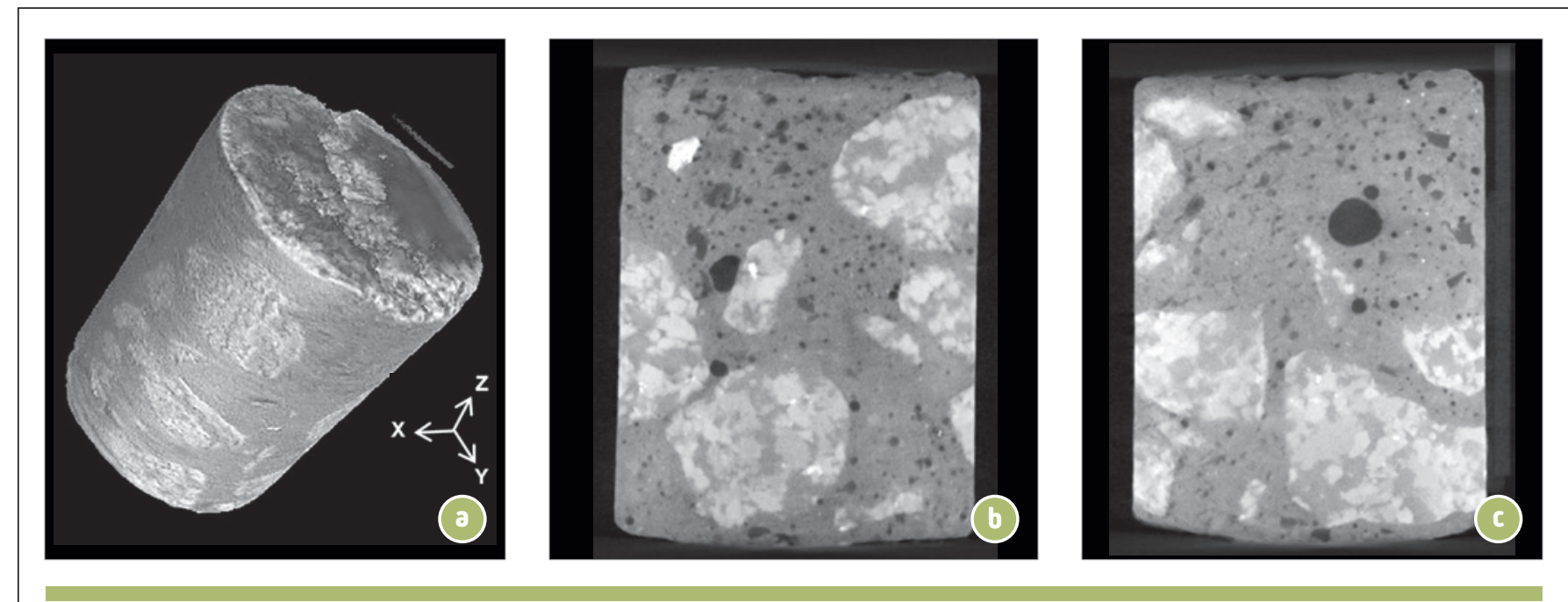

Figura 4

BOR10\%: (a) imagem tridimensional da amostra (b) imagem bidimensional conforme eixo ZX e (c) conforme eixo ZY

vazios nas amostras contendo resíduos de pneus inservíveis e do espaço ocupado por fibras metálicas recicladas em FIB0,5\% e FIB1,5\%, pode ser observada na Tabela 1. Ressalta-se que a avaliação do volume de vazios não foi realizada para o concreto referência, dada uma limitação para o número total de amostras ensaiadas.

Ao analisar a Tabela 1, é possí- vel notar que o traço BOR10\% possui maior percentual de vazios comparado ao traço BOR5\%. Esse comportamento já era esperado, uma vez que o aumento do teor de borracha reciclada incide no acréscimo de vazios de ar aprisionado na mistura (MEHERIER, 2016). Outro fator a ser apontado é que as amostras com borracha apresentam maiores índices de vazios do que as amostras com fibra, dada a tendência das partículas de borracha a promover o aprisionamento de ar.

Imagens tri e bidimensionais das amostras BOR5\% e BOR10\% podem ser observadas nas Figuras 3 e 4, respectivamente, com a indicação dos eixos cartesianos e imagens das seções internas e centrais das amostras. Nas imagens, as manchas maiores, de cor
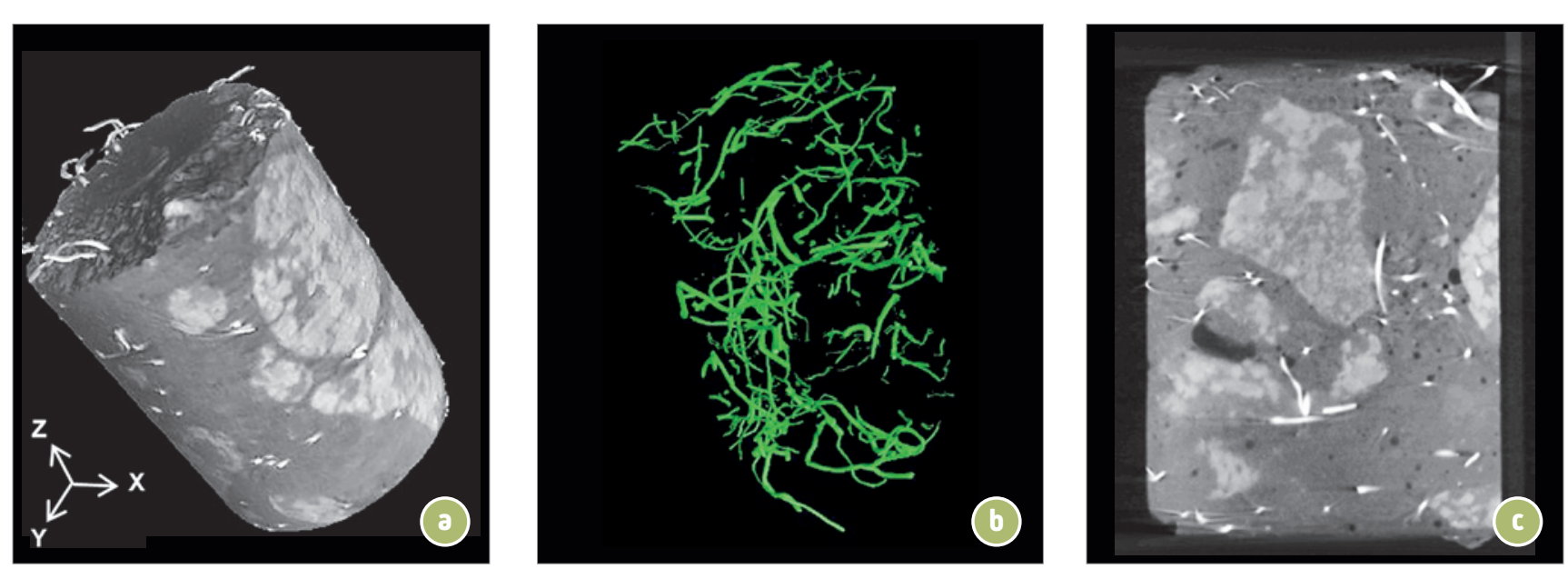

Figura 5

FIB0,5\%: (a) imagem tridimensional da amostra (b) imagem tridimensional da fibra metálica isolada e (c) imagem bidimensional da amostra conforme eixo ZY 


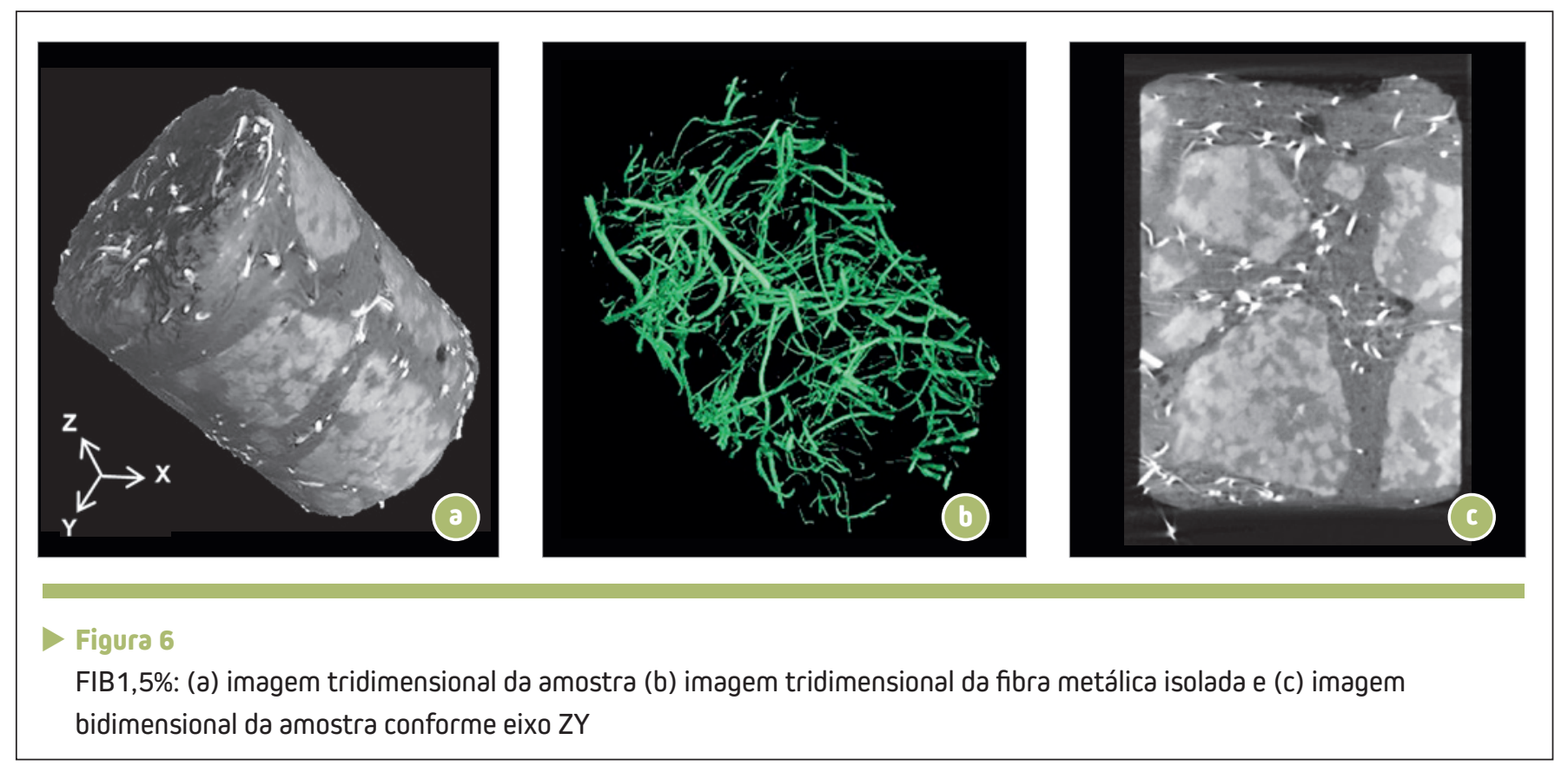

cinza-claro, representam o agregado graúdo, já as manchas pretas menores representam as partículas de borracha.

As Figuras 3 e 4 evidenciam a distribuição interna do agregado reciclado de borracha, mostrando que as partículas de borracha não possuíam tamanho ou formato padrão e estavam dispersas de forma parcialmente homogênea. Não houve evidência de acúmulo acentuado de borracha reciclada em nenhuma região da amostra, mostrando a boa capacidade de dispersão do resíduo na matriz cimentícia.
Imagens tri e bidimensionais das amostras FIB0,5\% e FIB1,5\% podem ser observadas nas Figuras 5 e 6 , respectivamente, com a indicação dos eixos cartesianos e imagens das seções internas e centrais das amostras. Nas imagens, as manchas maiores, em cinza-claro, representam o agregado graúdo, já os elementos claros e alongados representam as fibras metálicas recicladas.

A dispersão interna da fibra metálica apresentada nas Figuras 5 e 6 reforça que as fibras não possuíam tamanho padrão e estavam dispersas de forma parcialmente homogênea. Não houve evidência de acúmulo acentuado de fibra metálica reciclada em nenhuma região da amostra para tomografia computadorizada.

Cabe salientar que as amostras para o tomógrafo são pequenas, mas foram extraídas de placas com maiores dimensões justamente para tentar reproduzir a dispersão mais próxima de uma peça maior.

\subsection{Abatimento de tronco de cone}

Os resultados obtidos no ensaio de abatimento de tronco de cone para os diferentes concretos confeccionados podem ser observados na Figura 7. É possível observar que a inserção de resíduo de pneu, sejam partículas de borracha ou fibra metálica, ocasionaram a redução da trabalhabilidade do concreto, concordando com outros estudos encontrados na literatura (FIGUEIREDO; CECCATO, 2015; MEHERIER, 2016).
Figura 7

Resultados do ensaio de abatimento de tronco de cone 
Cabe salientar que a redução do abatimento constatada nos traços com agregado reciclado de borracha e FIB0,5\% não impediu ou causou prejuízo significativo para a moldagem das amostras. Já em FIB1,5\%, devido à formação de grumos no concreto fresco, houve dificuldade de moldagem dos corpos de prova cilíndricos. Para o traço FIB1,5\%, onde se registraram aglomerados de fibras metálicas recicladas durante a moldagem, a redução foi de $63 \%$ quando comparado ao REF.

\subsection{Resistência à compressão}

Os resultados obtidos para resistência à compressão podem ser observados na Figura 8, sendo destacados os valores médios de cada traço com respectivo desvio padrão. De forma geral, a resistência à compressão dos concretos com e sem resíduos apresentaram comportamento de crescimento ao longo do tempo, como esperado.

A mistura BOR5\% apresentou resistência à compressão 9\% inferior em relação à mistura referência, resultado esperado, já que a maioria dos trabaIhos envolvendo a adição ou a substituição de fragmentos de pneu na matriz cimentícia observaram a redução da resistência à compressão (BAUER et al., 2018; MEHERIER, 2016). O traço BOR10\% indicou resistência à compressão $8 \%$ superior em relação ao traço referência, resultado impremeditável, todavia encontrado por Santos et al. (2017).

O traço $\mathrm{FIBO}, 5 \%$ apresentou resistência à compressão 7\% superior à mistura referência, sendo um resultado compatível com outras pesquisas experimentais em concretos reforçados com fibra de aço com percentuais de inserção

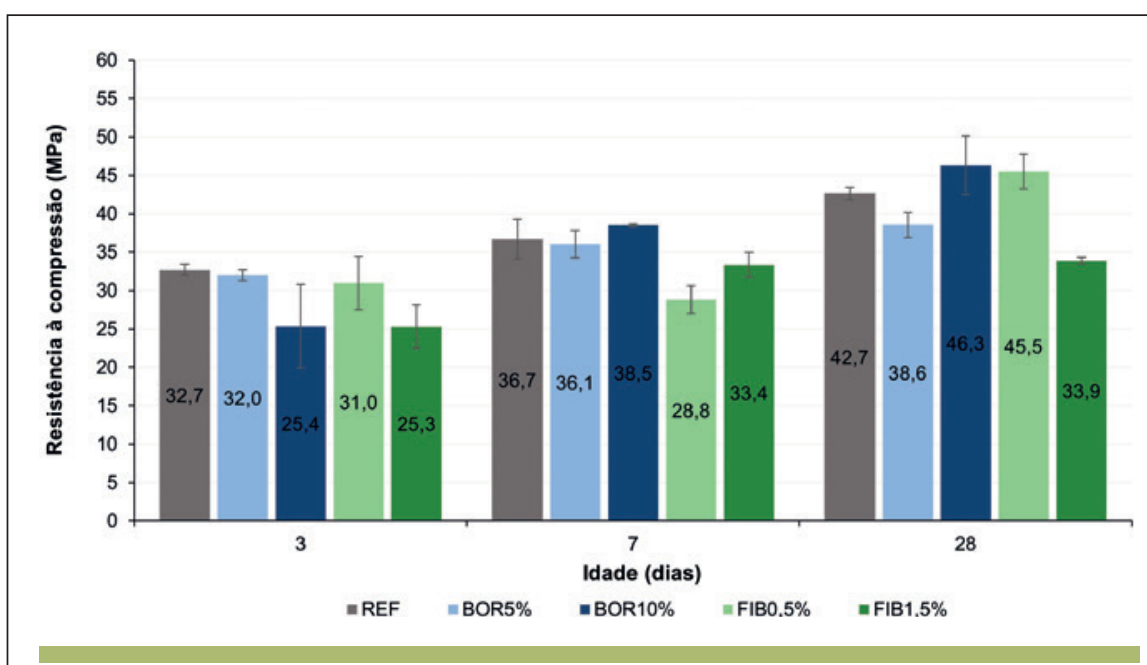

Figura 8

Valores médios obtidos de resistência à compressão

de até $2 \%$, os quais também registraram moderado acréscimo na resistência à compressão (BATISTA et al., 2018; GIL et al., 2018). A mistura FIB1,5\% indicou resistência à compressão 21\% inferior à mistura referência, sendo expectável devido aos grumos de fibras observados durante a moldagem.

Para avaliar a resistência à compressão das misturas elaboradas, com idade de ensaio aos 28 dias, foi realizada análise de variância e os resultados estão apresentados na Tabela 2. Com nível de confiança de 95\% e com relação à resistência à compressão, é possível constatar que há diferença significativa apenas entre os percentuais testados.

Com o teste de Tukey (Tabela 3), foi possível realizar o agrupamento dos resultados homogêneos conside- rando cada variável, o que serviu para complementar os resultados da análise de variância.

O teste de Tukey indicou que as misturas REF, FIB0,5\% e BOR10\% estão contidas no grupo 2 e possuem valores de resistência à compressão superiores ao grupo 1, em particular FIB1,5\%. A mistura BOR5\% está contida nos dois grupos, apresentando similaridade estatística em seus dados com ambos os agrupamentos. Essa análise corrobora que $\mathrm{FIB1}, 5 \%$ apresenta os resultados de resistência à compressão mais baixos.

\subsection{Módulo de elasticidade}

Os resultados obtidos para módulo de elasticidade podem ser
Tabela 2 - Análise de variância dos resultados de resistência à compressão

\begin{tabular}{|ccccc|}
\hline Variável & $\begin{array}{c}\text { Graus de } \\
\text { liberdade }(\mathrm{gl})\end{array}$ & $\begin{array}{c}\text { Soma dos } \\
\text { quadrados (SQ) }\end{array}$ & $\begin{array}{c}\text { Quadrado } \\
\text { médio (MQ) }\end{array}$ & p-valor \\
\hline Material & 2 & 18,883 & 9,442 & 0,225 \\
\hline Percentuais & 2 & 194,622 & 97,311 & 0,004 \\
\hline Resíduos & 5 & 23,130 & 4,626 & - \\
\hline
\end{tabular}


Tabela 3 - Agrupamento de resultados de resistência à compressão conforme teste de Tukey

\begin{tabular}{|c|c|c|c|c|c|}
\hline Percentual & Material & Média ajustada & $\begin{array}{l}\text { Intervalo inferior } \\
\text { de confiança }\end{array}$ & $\begin{array}{l}\text { Intervalo superior } \\
\text { de confiança }\end{array}$ & Grupo \\
\hline $1,5 \%$ & $\mathrm{~F}$ & 33,900 & 27,799 & 40,001 & 1 \\
\hline $5 \%$ & $B$ & 38,550 & 32,449 & 44,651 & 1 e 2 \\
\hline $0 \%$ & REF & 42,650 & 36,549 & 48,751 & 2 \\
\hline $0,5 \%$ & $\mathrm{~F}$ & 45,500 & 39,999 & 51,601 & 2 \\
\hline $10 \%$ & B & 46,300 & 40,199 & 52,401 & 2 \\
\hline
\end{tabular}

Legenda: (B) concreto com agregado reciclado de borracha; (F) concreto com fibra metálica reciclada; (REF) concreto referência.

observados na Figura 9, sendo destacados os valores médios de cada traço com respectivo desvio padrão, idade de 28 dias.

Os resultados de módulo de elasticidade predispõem a mesma tendência dos resultados de resistência à compressão, uma vez que são duas propriedades relacionadas. O traço FIB1,5\% apresentou o menor valor de resistência à compressão e de mó- dulo de elasticidade. Para o concreto com substituição de agregado de borracha reciclada, o módulo de elasticidade se mostrou menos sensível à variação no teor de borracha do que a resistência mecânica.

Para avaliar o módulo de elasticidade, com idade de ensaio aos 28 dias, foi realizada análise de variância e os resultados estão apresentados na Tabela 4. Com nível de confiança

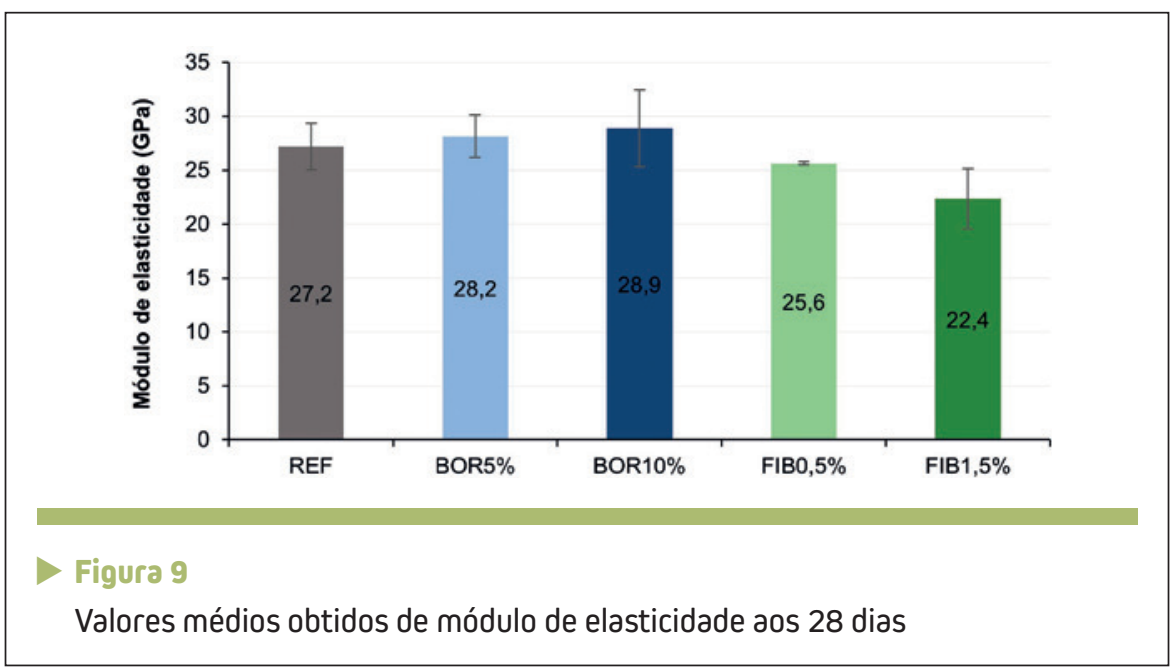

Tabela 4 - Análise de variância dos resultados de módulo de elasticidade

\begin{tabular}{|ccccc|}
\hline Variável & $\begin{array}{c}\text { Graus de } \\
\text { liberdade }(\mathrm{gl})\end{array}$ & $\begin{array}{c}\text { Soma dos } \\
\text { quadrados (SQ) }\end{array}$ & $\begin{array}{c}\text { Quadrado } \\
\text { médio (MQ) }\end{array}$ & p-valor \\
\hline Material & 2 & 63,472 & 31,736 & 0,025 \\
\hline Percentuais & 2 & 16,904 & 8,452 & 0,277 \\
\hline Resíduos & 10 & 57,741 & 5,774 & - \\
\hline
\end{tabular}

de 95\% e com relação ao módulo de elasticidade, é possível constatar que há diferença significativa apenas entre os materiais reciclados empregados.

Com o teste de Tukey (Tabela 5), foi possível realizar o agrupamento dos resultados homogêneos considerando cada variável, o que serviu para complementar os resultados da análise de variância.

O teste de Tukey indicou que as misturas com fibra metálica (grupo 1) e com borracha (grupo 2) estão em grupos opostos, evidenciando a diferenciação entre os materiais em relação ao módulo de elasticidade. O concreto referência está contido nos dois grupos, apresentando similaridade estatística em seus dados com ambos os grupos. Em relação ao concreto com inserção de fibra metálica reciclada, a ferramenta estatística não registrou a diferença observada entre $\mathrm{FIBO}, 5 \%$ e $\mathrm{FIB} 1,5 \%$.

\section{CONCLUSÕES}

O objetivo deste trabalho foi avaliar o comportamento de concretos, elaborados com material reaproveitado de pneus inservíveis, através da caracterização da trabalhabilidade no estado fresco e das propriedades físicas e mecânicas no estado endurecido. Considerando os materiais e 
os métodos utilizados no programa experimental, bem como os resultados obtidos, tem-se as seguintes conclusões:

- A incorporação de partículas de borracha no concreto tende a incrementar a incorporação de ar, fenômeno que deve ser levado em consideração quando se usa esse tipo de compósito;

$\checkmark$ No estado fresco, observou-se redução da trabalhabilidade para todos os concretos com resíduos em relação ao concreto referência. No entanto, para os traços BOR5\%, BOR10\% e FIB0,5\% a redução da trabalhabilidade não prejudicou o processo de moldagem das amostras;

> Considerando a resistência à compressão e o módulo de elasticidade dos concretos BOR5\% e BOR10\%, a análise estatística não constatou prejuízo significativo para essas propriedades mecânicas, indicando a possibilidade eficaz de substituição de agregado miúdo por agregado reciclado de borracha;

Tabela 5 - Agrupamento de resultados de módulo de elasticidade conforme teste de Tukey

\begin{tabular}{ccccc} 
Material & Média ajustada & $\begin{array}{c}\text { Intervalo } \\
\text { inferior de } \\
\text { confiança }\end{array}$ & $\begin{array}{r}\text { Intervalo } \\
\text { superior de } \\
\text { confiança }\end{array}$ & Grupo \\
\hline F & 24,000 & 21,195 & 26,806 & 1 \\
\hline REF & 27,208 & 23,240 & 31,176 & 1 e 2 \\
\hline B & 28,521 & 25,716 & 31,327 & 2 \\
\hline
\end{tabular}

Legenda: (B) concreto com agregado reciclado de borracha; ( $F$ ) concreto com fibra metálica reciclada; (REF) concreto referência.

A avaliação da resistência à compressão e do módulo de elasticidade de $\mathrm{FIB0}, 5 \%$ indicou a possibilidade eficiente de inserção de fibra metálica reciclada no concreto para esse teor. No entanto, a redução da trabalhabilidade e das propriedades mecânicas aferidas para FIB1,5\% apontam que o teor de 1,5\% parece ser o limite de inserção para esse material reciclado no concreto;

> Quanto ao formato da fibra metálica reciclada, é importante padronizar a sua forma para facilitar a manipulação e a dispersão do resíduo durante a mistura do concreto.
Por fim, no que diz respeito aos resíduos de pneus inservíveis, fibra metálica reciclada e agregado reciclado de borracha, o reaproveitamento desses materiais no concreto pode trazer benefícios para a construção civil e para o meio ambiente, através do ganho ambiental e do desenvolvimento sustentável.

\section{AGRADECIMENTOS}

Os autores gostariam de agradecer à Construtora Premold e à Industrial Batistella de Artefatos de Borracha Ltda. pelo apoio operacional e pela doação de materiais para o programa experimental.

\section{DREFER̂NCIAS BIBLIOGRÁFICAS}

[1] ASSOCIAÇÃO BRASILEIRA DE NORMAS TÉCNICAS. NBR NM 67: Concreto - Determinação da consistência pelo abatimento do tronco de cone. Rio de Janeiro, 1998 (norma cancelada).

[2] ASSOCIAÇÃO BRASILEIRA DE NORMAS TÉCNICAS. NBR 8522: Concreto - Determinação dos módulos estáticos de elasticidade e de deformação à compressão. Rio de Janeiro, 2017.

[3] ASSOCIAÇÃO BRASILEIRA DE NORMAS TÉCNICAS. NBR 5739: Concreto - Ensaios de compressão de corpos de prova cilíndricos. Rio de Janeiro, 2018.

[4] BATISTA, A. J. A. et al. Propriedades mecânicas de concretos com incorporação de fibra de aço reciclada de pneus inserviveis. In: Congresso Brasileiro do Concreto, 60, 2018. Anais [...]. Foz do Iguaçu: Instituto Brasileiro do Concreto, 2018.

[5] BAUER, A. L. et al. Avaliação das propriedades mecânicas de concretos com inserção de resíduos de borracha de pneu inservivel. In: Congresso Brasileiro do Concreto, 60, 2018. Anais [...]. Foz do Iguaçu: Instituto Brasileiro do Concreto, 2018.

[6] FIGUEIREDO, A. D. DE; CECCATO, M. R. Workability analysis of steel fiber reinforced concrete using slump and Ve-Be test. Materials Research, v. 18, n. 6, p. 1284-1290, 2015

[7] GIL, A. M. et al. Dosagem de concretos autoadensáveis reforçados com fibras de aço. In: Congresso Brasileiro do Concreto, 60, 2018. Anais [...]. Foz do lguaçu: Instituto Brasileiro do Concreto, 2018.

[8] MEHERIER, M. S. Investigation of mechanical and durability properties of cement mortar and concrete with varying replacement levels of crumb rubber as fine aggregate. 2016. 127 f. Thesis (Degree of Master of Applied Science) - University of British Columbia, Kelowna, Canada, 2016.

[9] SANTOS, G. R. F. DOS et al. Análise de concreto com adição de resíduo de borracha de pneu. In: Congresso Brasileiro do Concreto, 59, 2018. Anais [...]. Bento Gonçalves: Instituto Brasileiro do Concreto, 2017. 